\title{
Adverse effects of chronic low dose-rate gamma-ray exposure ameliorated by environmental enrichment in mice
}

\author{
D. Takai ${ }^{*}$, A. Abe ${ }^{2}$, H. Miura ${ }^{2}$, I.B. Tanaka1, M. Saito' ${ }^{1}$, J.I. Komura1 \\ ${ }^{1}$ Department of Radiobiology, Institute for Environmental Sciences, 2-121 Hacchazawa, Takahoko, Rokkasho, \\ Aomori 039-3213, Japan \\ 2JAC Co. Itd., 1-2-7 Higashiyama, Meguro, Tokyo 153-0043, Japan
}

\begin{abstract}
\section{- Original article}

\section{*Corresponding authors: \\ Daisaku Takai, Ph.D., E-mail: dtakai@ies.or.jp \\ Revised: June 2020 \\ Accepted: July 2020}

Int. J. Radiat. Res., July 2021; 19(3): 543-550

DOI: $10.29252 /$ ijrr.19.2.543

Background: Chronic long-term irradiation of mice with low dose-rate (20 $\mathrm{mGy} /$ day) gamma rays significantly shortened their life spans due to neoplasms and significant suppression of their ability to eliminate transplanted tumors. Materials and Methods: Mice exposed to chronic 20 $\mathrm{mGy} /$ day gamma rays for 400 days and housed in an enriched environment (EE) were compared with those housed in a standard environment. Results: We demonstrate that an EE significantly ameliorates the suppression of transplanted tumors in mice exposed to chronic low dose-rate gamma rays. Peripheral blood analysis revealed that the proportions of some immune cells were increased by EE housing. Additionally, the number and activity of natural killer (NK) cells in the peripheral blood increased with EE housing, indicating that NK cells may be involved in enhancing the ability to reject transplanted tumors. Conclusion: To our knowledge, this is the first study to report that the adverse effects, such as the suppression of tumor rejection activity of chronic low dose-rate irradiation exposure, may be alleviated by EE housing, which suggests the possibility that the adverse effects of irradiation may be mitigated by changes in lifestyle.
\end{abstract}

Keywords: Environmental enrichment, low dose-rate irradiation, mouse, transplanted tumor.

\section{INTRODUCTION}

High dose-rate radiation and high dose radiation are known to lead to deleterious consequences, including cancers. Recently, interest in the carcinogenic effects of low dose-rate exposure has been increasing in response to occupational exposure, medical exposure, and nuclear power plant accidents such as in Chernobyl and Fukushima. The health effects of exposure to low dose-rate radiation are not well understood and are currently estimated by extrapolating the effects of high dose exposure based on the linear no-threshold model (1-6).

Tanaka et al. (7) showed that mice that are chronically exposed to gamma rays at low dose-rates (20 mGy/day) had a statistically significant short life span. Pathological data analysis showed that the short life span was primarily a result of early death from neoplasms $(8,9)$. Furthermore, long-term, low dose-rate irradiation in mice has been shown to give rise to obesity (10) and weaken the immune system $(11,12)$. These physiological changes may affect antitumor immunity and cause the adverse effects of radiation. To alleviate the adverse effects of radiation, a healthy immune system activity may be necessary. Various methods, such as active and passive immunotherapy, have been developed to increase the antitumor immunity activity in-vivo (13).

Recently, an enriched environment (EE) has been reported to decrease tumor size, facilitate 
the rejection of transplanted tumor cells (14-19), and prolong the life spans of mice (20). EE has been defined as the use of housing conditions that enhance the sensory, motor, and cognitive stimulation of brain neuronal systems as compared with the standard caging, and it is also legally required within the European Union by Directive 2010/63/EU (21). It has been suggested that an EE affects the immune system and activates antitumor immunity through various pathways, resulting in enhanced tumor eradication and extended life span.

To our knowledge, no studies have shown that EE housing has any influence on radiation effects in mice. This report aimed to show whether an EE could alleviate the reduction in tumor rejection activity resulting from exposure to chronic low dose-rate gamma rays. The results of this study suggest the possibility that, even in humans, some lifestyle changes may mitigate the adverse effects of low dose-rate radiation exposure.

\section{MATERIALS AND METHODS}

\section{Animals and tumor cell lines}

Specific pathogen-free (SPF), six-week-old female $\mathrm{B}_{6} \mathrm{C} 3 \mathrm{~F}_{1}$ mice were purchased from a commercial breeding facility (Japan CLEA, Tokyo, Japan). After a two-week quarantine and acclimation, the mice were randomly divided into two groups, namely, irradiated (IR group, $\mathrm{n}$ $=95$ ) and nonirradiated control ( $\mathrm{C}$ group, $\mathrm{n}=102$; figure $1 \mathrm{~A}$ ). All of them were housed in an SPF facility maintained at a temperature of $23^{\circ} \mathrm{C}$ $\pm 2{ }^{\circ} \mathrm{C}$, with $50 \% \pm 10 \%$ humidity, and a 12 -h light/dark cycle, and given ad libitum access to commercially prepared and gamma-sterilized feed pellets (FR-2; Funabashi Farm Co., Chiba, Japan) and chlorinated drinking water. The mice were housed in groups of four in a plastic cage (TM-TPX-10, $218 \mathrm{~W} \times 320 \mathrm{D} \times 133 \mathrm{H} \mathrm{mm}$, floor area of $481 \mathrm{~cm}^{2}$; Tokiwa Kagaku Kikai Co., Tokyo, Japan) with sawdust bedding.

The tumor cell line OV3121 derived from an ovarian granulosa cell tumor that formed in a female B6C3F1 mouse (22) exposed to ${ }^{60} \mathrm{Co}$ gamma rays at a high dose-rate was purchased

\section{4}

from Health Science Research Resources Bank (Osaka, Japan).

The experiments were conducted in accordance with the legal regulations in the Fundamental Guidelines for Proper Conduct of Animal Experiment and Related Activities in Academic Research Institutions under the jurisdiction of the Ministry of Education, Culture, Sports, Science and Technology of Japan and the Guidelines for Animal Experiments of the Institute for Environmental Sciences.

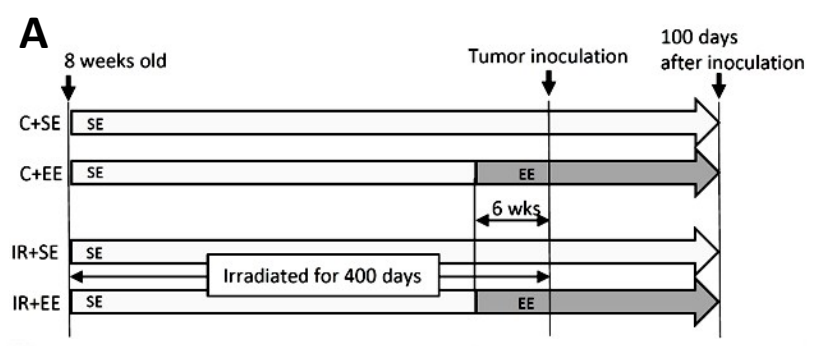

B Standard Environment
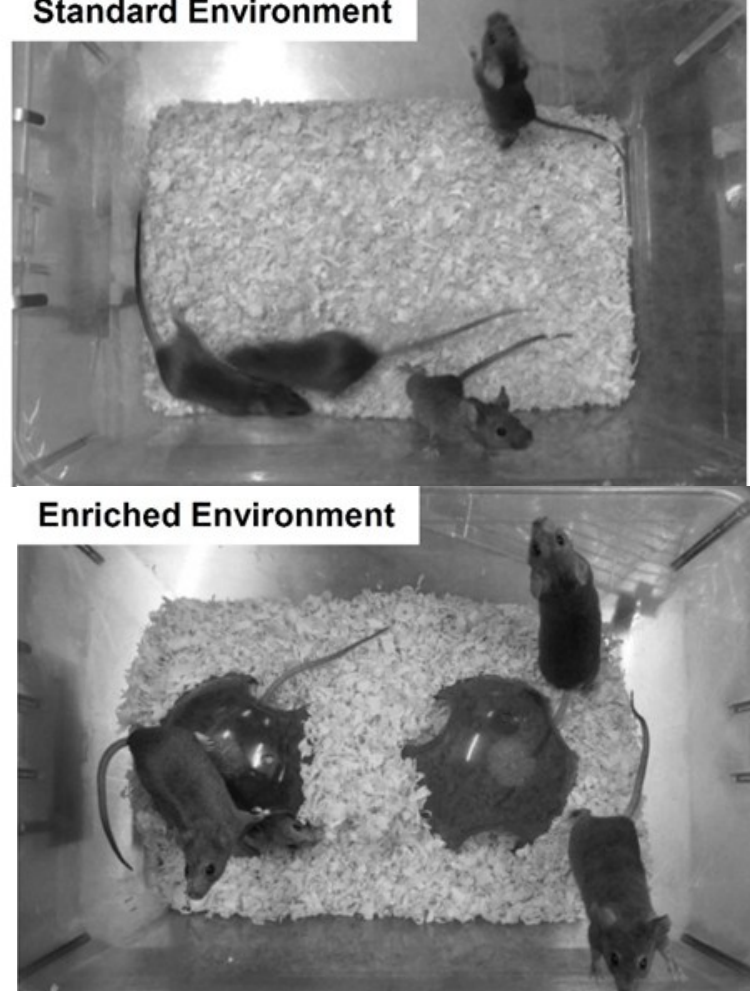

Figure 1. Experimental design. A. Schematic diagram of the experimental protocol. B. Four mice were housed in a cage of the standard (left) and enriched environments with two igloos (right).

\section{Irradiation}

The eight-week-old mice in the IR group were continuously irradiated with ${ }^{137} \mathrm{Cs}$ gamma rays at a low dose-rate of $20 \mathrm{mGy}$ for $22 \mathrm{~h}$ a day (74 Int. J. Radiat. Res., Vol. 19 No. 3, July 2021 
GBq, TYR-1501, Yoshizawa LA Co. Ltd., Chiba, Japan) for 400 days. The dose rate was measured using a glass dosimeter (GD-302M, AGC Techno Glass Co., Ltd., Shizuoka, Japan) and a reader (Dose Ace FGD-1000, AGC Techno Glass Co., Ltd.). The mice were transferred to the animal rooms after 400 days of irradiation with a total dose of 8,000 mGy (figure 1A).

\section{Environmental enrichment}

To environmentally enrich the standard housing, two mouse igloos (BioServ, Flemington, $\mathrm{NJ}$ ) were added to each cage for half of the mice in the IR (IR+EE group, $n=48)$ and $C(C+E E$ group, $n=52$ ) group (figure $1 B$ ) at six weeks prior to tumor cell inoculation. Every week, the igloos were replaced with clean units. Mice (IR+SE group, $n=47$ and $C+S E$ group, $n=50$ ) in $\mathrm{SE}$ housing remained in the same cages. Dose rate differences in EE devices were measured by placing a glass dosimeter inside and outside the igloos.

\section{Tumor cell transplantation}

Cultured OV3121 cells were trypsinized and suspended in normal saline to obtain cell suspensions of $1 \times 10^{6} \mathrm{cells} / \mathrm{ml}$. Cell suspensions $\left(0.1 \mathrm{ml}\right.$ including $1 \times 10^{5}$ cells) were subcutaneously inoculated into the backs of the mice. Twice a week, the mice were examined by manual palpation for tumor formation and development. The number of tumor-bearing mice (with palpable tumors) detected during the 100-day observation period after inoculation was counted.

\section{Cytotoxic activity of natural killer (NK) cells}

After the mice were euthanized with $\mathrm{CO}_{2}$, whole blood and spleens were collected aseptically. Erythrocytes were lysed using BD PharmLys (BD Biosciences, San Jose, CA). Lymphocytes were then collected. Yac-1 cells (DS Pharma Biomedical Co., Ltd, Osaka, Japan) were labeled using bromodeoxyuridine as described in the manual for Cellular DNA Fragmentation ELISA (Merck KGaA, Darmstadt, Germany) and co-cultured with lymphocytes for $4 \mathrm{~h}$; then, supernatants were collected for analyses. Cytotoxic activities were analyzed in accordance with the procedure for measuring cell-mediated cytotoxicity from Cellular DNA Fragmentation ELISA.

\section{Flow cytometric analysis}

Lymphocytes were stained with 7aminoactinomycin D (7-AAD) and antibodies of fluorescein isothiocyanate conjugated anti-mouse cluster of differentiation (CD) 335, phycoerythrin (PE) conjugated anti-mouse F4/80, PE-cyanine (Cy) 7 conjugated anti-mouse CD8a, PE-Cy5 conjugated anti-mouse CD4, allophycocyanin (APC) conjugated anti-mouse CD11c, APC-Cy7 conjugated anti-mouse CD11b, and PE-Texas red conjugated anti-mouse CD45R (BD Biosciences). FACS Fusion $^{\text {TM }}$ (BD Biosciences) was used to calculate cell proportions as 7-AAD-negative and antibody-positive cells.

\section{Statistical analysis}

Differences in tumor cell rejection activity between mice housed in EE and SE were examined using the log-rank test. Body weight, cytotoxic activity, and cell proportion were examined using the Tukey-Kramer test. $P$ less than 0.05 was considered statistically significant.

\section{RESULTS}

Blood samples and spleens were obtained from four mice in each group $(C+S E, C+E E, I R$ $+\mathrm{SE}$, and $\mathrm{IR}+\mathrm{EE}$ ) after completing radiation exposure (or six weeks after installing the igloos in the EE groups) prior to tumor inoculation. All the remaining mice $(C+S E, n=46 ; C+E E, n=48$; $\mathrm{IR}+\mathrm{SE}, \mathrm{n}=43$; IR+EE, $\mathrm{n}=44$ ) were inoculated with tumor cells and monitored for tumor formation for 100 days after inoculation.

After irradiation, the average body weights of mice were $46.07 \pm 7.00 \mathrm{~g}(\mathrm{C}+\mathrm{SE}, \mathrm{n}=50)$, $43.17 \pm 7.69 \mathrm{~g}(\mathrm{C}+\mathrm{EE}, \mathrm{n}=52), 49.64 \pm 4.06 \mathrm{~g}(\mathrm{IR}+\mathrm{SE}$, $\mathrm{n}=47)$, and $47.74 \pm 4.97 \mathrm{~g}(\mathrm{IR}+\mathrm{EE}, \mathrm{n}=48)$. Body weights were significantly increased in mice with irradiation $(\mathrm{C}+\mathrm{SE}$ vs. $\mathrm{IR}+\mathrm{SE}, \mathrm{p}<0.01 ; \mathrm{C}+\mathrm{EE}$ vs. IR+EE, $p<0.01$ ) and tended to decrease in mice housed in an EE (figure 2A). Although there 
was a tendency for an earlier occurrence of palpable tumors after tumor cell inoculation in heavier mice, no significant correlation was observed (figure $2 \mathrm{~B}, \mathrm{r}^{2}=0.073$ ).

Peripheral blood analysis using flow cytometry (figure $3 \mathrm{~A}$ ) revealed that proportions of $\mathrm{CD}_{11 \mathrm{c}^{+}}, \mathrm{CD} 45 \mathrm{R}^{+}$, and $\mathrm{F} 4 / 80^{+}$cells were considerably increased by EE housing ( $\mathrm{C}+\mathrm{SE}$ vs. $\mathrm{C}+\mathrm{EE}$ and IR+SE vs. IR+EE) and tended to increase with radiation exposure $(\mathrm{C}+\mathrm{SE}$ vs. $\mathrm{IR}+\mathrm{SE}$ and $\mathrm{C}+\mathrm{EE}$ vs. IR+EE). The proportion of $\mathrm{CD}_{33}{ }^{+}$cells exhibited a tendency to increase in EE housing ( $\mathrm{C}+\mathrm{SE}$ vs. $\mathrm{C}+\mathrm{EE}$ and IR+SE vs. IR+EE) but significantly decreased with radiation exposure (C+SE vs. IR+SE and C+EE vs. IR+EE).

In the spleen (figure $3 \mathrm{~B}$ ), proportions of

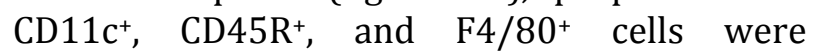
significantly increased by EE housing ( + SE vs. $\mathrm{C}+\mathrm{EE}$ and IR+SE vs. IR+EE). Proportions of $\mathrm{CD}_{33}{ }^{+}$cells were significantly increased by EE housing $(\mathrm{C}+\mathrm{SE}$ vs. $\mathrm{C}+\mathrm{EE}$ and IR+SE vs. IR+EE) and decreased by radiation exposure $(\mathrm{C}+\mathrm{EE}$ vs. IR+EE).

Cytotoxic activities of NK cells in these mice were examined by lysing the target Yac-1 cells.
In peripheral lymphocytes, activities tended to abate after chronic low dose-rate radiation ( $\mathrm{C}+\mathrm{SE}$ vs. IR+SE and $\mathrm{C}+\mathrm{EE}$ vs. IR+EE; figure $3 \mathrm{~A}$ ). Similar to changes in the proportion of CD335+ cells, decreased cytotoxic activity after radiation exposure may be improved by $\mathrm{EE}$ housing. However, the effects of EE on the cytotoxic activity of NK cells in the spleen did not follow a pattern (figure 3B) similar to that of peripheral lymphocytes.

All the other mice $(C+S E, n=46$; $C+E E, n=48$; IR+SE, $n=43$; IR+EE, $n=44$ ) were inoculated with $1 \times 10^{5}$ OV3121 cells and inspected for tumor formation (figure 4). Chronic low dose-rate gamma-ray exposure significantly suppressed the antitumor activity $(p<0.001[\mathrm{C}+\mathrm{SE}$ vs. IR+SE and $\mathrm{C}+\mathrm{EE}$ vs. IR+EE] in the log-rank test). Decreased antitumor activity was significantly alleviated in mice housed in an $\operatorname{EE~}(p=0.028$, $\mathrm{C}+\mathrm{SE}$ vs. $\mathrm{C}+\mathrm{EE}$ in the log-rank test), even after the onset of gamma-ray exposure ( $p=0.032$, $\mathrm{IR}+\mathrm{SE}$ vs. IR+EE in the log-rank test). Tumor induction between the IR+EE and $\mathrm{C}+\mathrm{SE}$ groups was not significantly different ( $p=0.099)$.

\section{A. Body Weight}

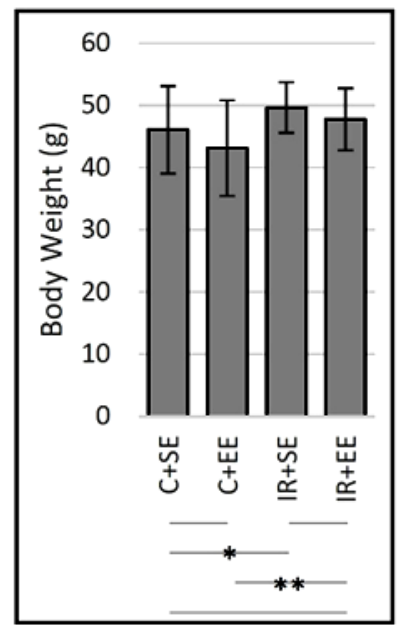

\section{B. Correlation of body weight and tumor arising day}

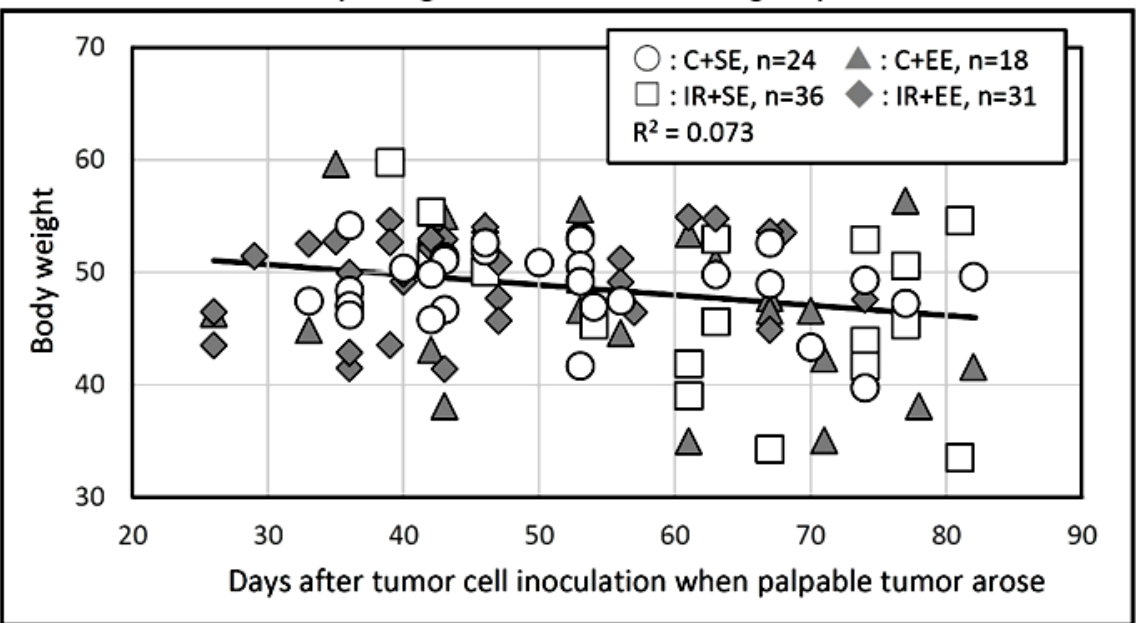

Figure 2. A. The average body weight of mice in each group ( $C+S E, n=50 ; C+E E, n=52 ; I R+S E, n=47 ; I R+E E, n=48)$.

B. Correlation between body weight during tumor cell inoculation and the day of tumor occurrence. Bar, standard deviation; *, $\mathrm{P}$ $<0.05 ; *$, $\mathrm{P}<0.01$ (t-test). 
A. Peripheral Blood

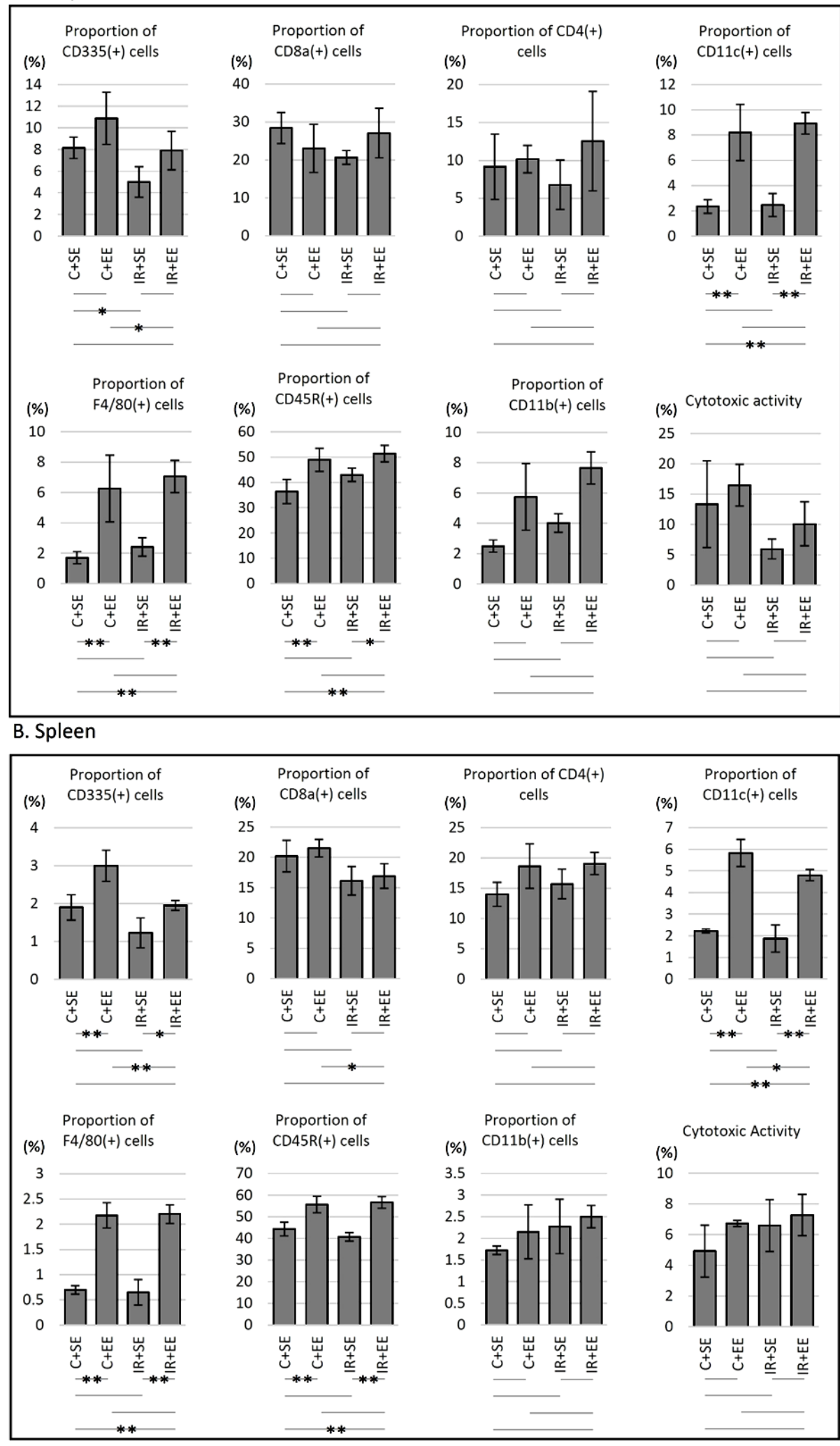

Figure 3. Results of flow cytometric analysis showing proportions of CD335-, CD8a-, CD4-, CD11C-, F4/80-, CD45R-, and CD11b-positive cells and results of NK cell activity in (A) the peripheral blood and (B) spleen of each group ( $n=4$, respectively). Bar, standard deviation; *, $\mathrm{P}<0.05 ; * *, \mathrm{P}<0.01$ (t-test). 


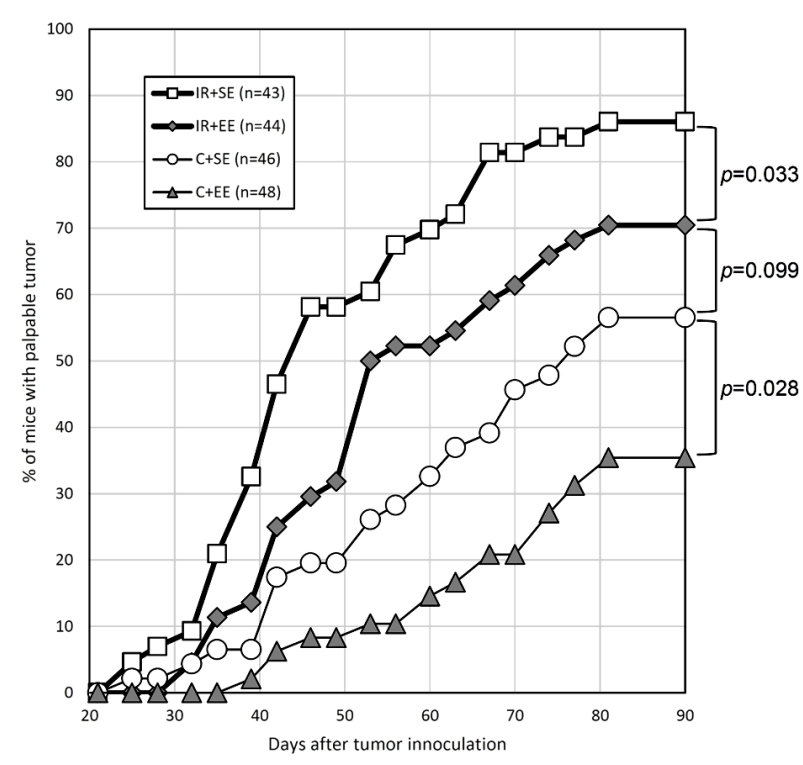

Figure 4. Comparison of transplanted tumor cell rejection activity. P-values were calculated using the log-rank test.

\section{DISCUSSION}

To the best of our knowledge, this is the first study to report the possibility that after low dose-rate irradiation, some lifestyle modifications may mitigate the adverse effects of irradiation. This report provides important tips for mitigating the adverse effects of low dose-rate radiation that people who are inevitably exposed to it may experience such as nuclear workers and residents near nuclear power plants.

A previous report (19) demonstrated that the addition of one igloo can adequately enhance tumor rejection. However, one igloo did not have any effect on tumor suppression when mice aged over 400 days were used in the experiment. Based on the body weights of mice at 456 days ( $>40 \mathrm{~g}$, figure $2 \mathrm{~A}$ ), four mice in one cage were presumed to be too big/heavy to fit in one igloo; hence, in this study, two igloos were installed in each cage (figure 1B) to provide enough space for all the mice.

The dose rate in an igloo was approximately $3 \%$ lower than that of the outside. Igloos were installed for six weeks, resulting in a lower total dose in IR + EE (approximately 7,975 mGy) than that in IR + SE (8,000 mGy) groups. The $25 \mathrm{mGy}$ difference was considered small and could be disregarded.

As in previous reports $(7,8,10)$, chronic low dose-rate gamma-ray exposure increased the body weights of mice (figure 2A; $p<0.01$; $C+$ SE vs. IR + SE and C + EE vs. IR + EE). EE housing reduced the weight gain attributed to radiation exposure at the same level as the nonirradiated controls $(p>0.05 ; \mathrm{C}+\mathrm{SE}$ vs. IR + EE). Although additional devices for exercise (e.g., a running wheel) were not installed, mice housed in an EE weighed less than those in an SE after six weeks. The mechanisms for lower body weight are unclear. Although body weight at the time of tumor inoculation may have affected the tumor rejection response, body weight was not correlated with tumor rejection (figure 2B).

Both radiation exposure and EE housing impacted the proportion of cells in the peripheral blood and spleens (figure $3 \mathrm{~A}$ and $\mathrm{B}$ ). The proportions of $\mathrm{CD} 11 \mathrm{c}^{+}, \mathrm{F} 4 / 80^{+}$, and $\mathrm{CD} 45 \mathrm{R}^{+}$ cells were not significantly affected by radiation $(\mathrm{C}+\mathrm{SE}$ vs. $\mathrm{IR}+\mathrm{SE}$ and $\mathrm{C}+\mathrm{EE}$ vs. IR+EE), unlike in $\mathrm{EE}$ housing $(\mathrm{C}+\mathrm{SE}$ vs. $\mathrm{C}+\mathrm{EE}$ and $\mathrm{IR}+\mathrm{SE}$ vs. IR+EE), indicating that changes in the proportion of these cells could not explain the changes in tumor rejection activity (figure 4). Differences in the proportion of $\mathrm{CD}_{33} 5^{+}$cells (a marker of NK cells) indicated that EE housing $(\mathrm{C}+\mathrm{SE}$ vs. IR+EE) ameliorated its decrease due to radiation exposure $(\mathrm{C}+\mathrm{SE}$ vs. $\mathrm{IR}+\mathrm{SE})$. Likewise, $\mathrm{EE}$ housing $(\mathrm{C}+\mathrm{SE}$ vs. $\mathrm{IR}+\mathrm{SE})$ ameliorated a decrease in the proportion of CD335+ cells in the spleen, unlike other cells. These changes in the proportions of $\mathrm{CD}_{3} 35^{+}$cells may account for the amelioration of the tumor rejection activity (figure 4).

Previous reports have shown that NK cells were involved in the enhancement of antitumor activity by EE housing $(14,18,23,24)$. A previous report (19) also found that administrations of anti -asialo GM1 antibody to mice reduced tumor rejection activity and neutralized the enhanced tumor rejection activity attributed to $\mathrm{EE}$ housing, suggesting that NK cells participate in the rejection of transplanted OV3121 cells in ${\mathrm{B} 6 \mathrm{C} 3 \mathrm{~F}_{1}}_{1}$ female mice. Consistent with past reports, the results shown in figure $3 \mathrm{~A}$ demonstrate that the reduction in activity due to radiation exposure recovers with EE housing. 
These improvements in NK cell activity may also explain the amelioration of the tumor rejection activity (figure 4).

In our previous reports, the tumor rejection activity was decreased by chronic low dose-rate gamma-ray exposure ${ }^{(11,12)}$ and increased with EE housing (19). The present study also shows similar results (figure 4), further supporting those of previous reports $(11,12)$. Compared with prior results (19), the degree of enhancement of tumor rejection activity in nonirradiated control mice was lower in this experiment (figure 4), which may have been due to differences in the age of the mice used, since the effect of an EE varies with age (25). These results indicate that the effect of an EE on older mice is lower than that in younger mice. Changes in the proportion of CD335 ${ }^{+}$cells and cytotoxic activity of NK cells (figure 3) follow trends similar to those of tumor rejection activity (figure 4), indicating that NK cells may be responsible for this tumor rejection activity. Importantly, decreased antitumor activity caused by radiation exposure (IR+SE) was suggested to alleviate the levels similar to that of the nonirradiated control without EE housing $(\mathrm{C}+\mathrm{SE}$ vs. IR+EE). These results demonstrate that adverse effects, such as cancer (8) and shortened life span (7), after chronic low dose-rate radiation exposures may be mitigated by EE housing, even when initiated after radiation exposure. However, lifestyle factors also play a significant role in the effects of radiation exposure on humans, and the role of rodent (mouse) housing environments on the effects of radiation exposure at a chronic low dose-rate should be studied further.

\section{CONCLUSION}

Environmentally enriched housing conditions in mice can alleviate the adverse effects of chronic low dose-rate gamma-ray exposure, which may involve NK cell activity. Therefore, findings from this study suggest a possibility that, after low-dose-rate irradiation, some lifestyle modifications may mitigate the adverse effects of irradiation.

\section{ACKNOWLEDGMENT}

We would like to thank Mr. M. Yoneya (Institute for Environmental Sciences) for providing technical assistance on bleeding mice. Dose rate measurements were supported by the CBS Corporation (Tokyo, Japan). This work was performed under a contract with the Aomori Prefectural Government, Japan.

Conflicts of interest: Declared none.

\section{REFERENCES}

1. Brenner DJ, Doll R, Goodhead DT, Hall EJ, Land CE, Little JB, Lubin JH, Preston DL, Preston RJ, Puskin JS, Ron E, Sachs RK, Samet JM, Setlow RB, Zaider M (2003) Cancer risks attributable to low doses of ionizing radiation: assessing what we really know. Proc Natl Acad Sci, USA 100: 13761 13766.

2. International Commission on Radiological Protection. The 2007 Recommendations of the International Commission on Radiological Protection. ICRP Publication 103: Ann ICRP 2007, 37.

3. International Commission on Radiological Protection (2005) Low-dose extrapolation of radiation-related cancer risk. ICRP Publication 99 Ann ICRP 2005, 35.

4. Dauer LT, Brooks AL, Hoel DG, Morgan WF, Stram D, Tran $P$ (2010) Review and evaluation of updated research on the health effects associated with low-dose ionising radiation. Radiat Prot Dosimetry, 140: 103-136.

5. Shah DJ, Sachs RK, Wilson DJ (2012) Radiation-induced cancer: a modern view. Br J Radiol, 85: e1166-1173.

6. Rühm W, Woloschak GE, Shore RE, Azizova TV, Grosche B, Niwa O, Akiba S, Ono T, Suzuki K, Iwasaki T, Ban N, Kai M, Clement CH, Bouffler S, Toma H, Hamada N. (2015) Dose and dose-rate effects of ionizing radiation: a discussion in the light of radiological protection. Radiat Environ Biophys, 54:379-401.

7. Tanaka S, Tanaka IB 3rd, Sasagawa S, Ichinohe K, Takabatake T, Matsushita S, Matsumoto T, Otsu H, Sato F (2003) No lengthening of life span in mice continuously exposed to gamma rays at very low dose rates. Radiat Res, 160: 376-379.

8. Tanaka IB 3rd, Tanaka S, Ichinohe K, Matsushita S, Matsumoto T, Otsu H, Oghiso Y, Sato F. (2007) Cause of death and neoplasia in mice continuously exposed to very low dose rates of gamma rays. Radiat Res, 167: 417-437.

9. Braga-Tanaka I 3rd, Tanaka S, Kohda A, Takai D, Nakamura S, Ono T, Tanaka K, Komura JI (2018) Experimental studies on the biological effects of chronic low dose-rate radiation 
exposure in mice: overview of the studies at the Institute for Environmental Sciences. Int J Rad Biol, 94: 423-433.

10. Nakamura S, Tanaka IB 3rd, Tanaka S, Nakaya K, Sakata N, Oghiso Y (2010) Adiposity in female B6C3F1 mice continuously irradiated with low-dose-rate gamma rays. Radiat Res, 173: 333-341.

11. Takai D, Todate A, Yanai T, Ichinohe K, Oghiso Y (2011) Enhanced transplantability of a cell line from a murine ovary granulosa cell tumour in syngeneic $\mathrm{B} 6 \mathrm{C} 3 \mathrm{~F}(1)$ mice continuously irradiated with low dose-rate gamma-rays. Int J Radiat Biol, 87: 729-735.

12. Takai D, Todate A, Ichinohe K, Komura JI (2015) Effects of chronic low-dose-rate gamma irradiation on the antitumor activity and chemokine system in mice. J Radiobiol, 2: 2429.

13. Peto J (2001) Cancer epidemiology in the last century and the next decade, Nature, 411: 390-395.

14. Cao L, Liu X, Lin EJ, Wang C, Choi EY, Riban V, Lin B, During MJ. (2010) Environmental and genetic activation of a brain -adipocyte BDNF/leptin axis causes cancer remission and inhibition, Cell, 142: 52-64.

15. Gurfein BT, Davidenko O, Premenko-Lanier M, Milush JM, Acree M, Dallman MF, Touma C, Palme R, York VA, Fromentin G, Darcel N, Nixon DF, Hecht FM (2014) Environmental enrichment alters splenic immune cell composition and enhances secondary influenza vaccine responses in mice. Mol Med, 20: 179-190.

16. Li G, Gan Y, Fan Y, Wu Y, Lin H, Song Y, Cai X, Yu X, Pan W, Yao M, Gu J, Tu H (2015) Enriched environment inhibits mouse pancreatic cancer growth and down-regulates the expression of mitochondria-related genes in cancer cells. Sci Rep, 5: 7856.

17. Wu Y, Gan Y, Yuan H, Wang Q, Fan Y, Li G, Zhang J, Yao M, Gu J, Tu H (2016) Enriched environment housing enhances the sensitivity of mouse pancreatic cancer to chemotherapeutic agents. Biochem Biophys Res Commun, 473: 593-
599.

18. Garofalo S, D'Alessandro G, Chece G, Brau F, Maggi L, Rosa A, Porzia A, Mainiero F, Esposito V, Lauro C, Benigni G, Bernardini G, Santoni A, Limatola C (2015) Enriched environment reduces glioma growth through immune and non -immune mechanisms in mice. Nat Commun, 6: 6623.

19. Takai D, Abe A, Miura H, Tanaka S, Komura JI (2019) Minimum environmental enrichment is effective in activating antitumor immunity to transplanted tumor cells in mice. Exp Anim, 68: 569-576.

20. Arranz L, De Castro NM, Baeza I, Maté I, Viveros MP, De la Fuente M (2010) Environmental enrichment improves agerelated immune system impairment: long-term exposure since adulthood increases life span in mice. Rejuvenation Res, 13: 415-428.

21. Directive 2010/63/EU of the European parliament and of the council of 22 September 2010 on the protection of animals used for scientific purposes.

22. Yanagihara $K$, Nii $M$, Tsumuraya $M$, Numoto $M$, Seito $T$, Seyama $T$ (1995) A radiation-induced murine ovarian granulosa cell tumor line: introduction of v-ras gene potentiates a high metastatic ability. Japan J Cancer Res, 86: 347356.

23. Meng $Z$, Liu $T$, Song $Y$, Wang $Q, X u D$, Jiang J, Li $M$, Qiao J, Luo X, Gu J, Tu H, Gan Y (2019) Exposure to an enriched environment promotes the terminal maturation and proliferation of natural killer cells in mice. Brain Behav $1 \mathrm{~m}$ mun, 77: 150-160.

24. Song $Y$, Gan $Y$, Wang $Q$, Meng $Z$, Li G, Shen Y, Wu Y, Li P, Yao M, Gu J, Tu H (2017) Enriching the housing environment for mice enhances their NK cell antitumor immunity via sympathetic nerve-dependent regulation of NKG2D and CCR5. Cancer Res, 77: 1611-1622.

25. Warren JM, Zerweck C, Anthony A (1982) Effects of environmental enrichment on old mice. Dev Psychobiol, 15: 13 $-18$. 